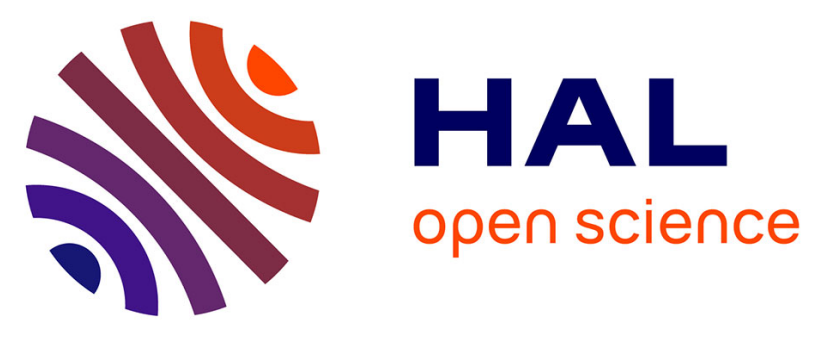

\title{
A Comparative Study of Fibromyalgia, Rheumatoid Arthritis, Spondyloarthritis, and Sjögren's Syndrome; Impact of the Disease on Quality of Life, Psychological Adjustment, and Use of Coping Strategies
}

\author{
Emilie Bucourt, Virginie Martaille, Philippe Goupille, Isabelle \\ Joncker-Vannier, Brigitte Huttenberger, Christian Réveillère, Denis \\ Mulleman, Robert Courtois
}

\section{- To cite this version:}

Emilie Bucourt, Virginie Martaille, Philippe Goupille, Isabelle Joncker-Vannier, Brigitte Huttenberger, et al.. A Comparative Study of Fibromyalgia, Rheumatoid Arthritis, Spondyloarthritis, and Sjögren's Syndrome; Impact of the Disease on Quality of Life, Psychological Adjustment, and Use of Coping Strategies. Pain Medicine, 2021, 22 (2), pp.372-381. 10.1093/pm/pnz255 . hal-02473512v2

HAL Id: hal-02473512

https: / hal-univ-tours.archives-ouvertes.fr/hal-02473512v2

Submitted on 20 Sep 2021

HAL is a multi-disciplinary open access archive for the deposit and dissemination of scientific research documents, whether they are published or not. The documents may come from teaching and research institutions in France or abroad, or from public or private research centers.
L'archive ouverte pluridisciplinaire HAL, est destinée au dépôt et à la diffusion de documents scientifiques de niveau recherche, publiés ou non, émanant des établissements d'enseignement et de recherche français ou étrangers, des laboratoires publics ou privés. 
Running title: Rheumatic diseases' impact and coping strategies

A comparative study of fibromyalgia, rheumatoid arthritis, spondyloarthritis and Sjogren's syndrome; impact of the disease on quality of life, psychological adjustment and use of coping strategies

\author{
Emilie Bucourt ${ }^{\text {a }}$ \\ Virginie Martaillé ${ }^{b}$ \\ Philippe Goupille ${ }^{\mathrm{b}}$ \\ Isabelle Joncker-Vannier ${ }^{\mathrm{c}}$ \\ Brigitte Huttenberger ${ }^{\mathrm{d}} \dagger$ \\ Christian Reveillere ${ }^{\text {a }}$ \\ Denis Mulleman $^{b}$ \\ Robert Courtois a e
}

a. Université de Tours; Département de psychologie; EE 1901 Qualipsy 'Qualité de vie et santé psychologique'; 37041 Tours cedex; France

b. Université de Tours; CHRU de Tours; Service de Rhumatologie; Tours; France

c. Université de Tours; CHRU de Tours; Consultation de la douleur; Tours; France

d. Université de Tours; CHRU de Tours; Service de Chirurgie Maxillo-Faciale; Plastique de la face et Stomatologie; Tours; France

e. CHRU de Tours; Clinique Psychiatrique Universitaire; 37044 Tours cedex; France

Correspondence to:

Robert Courtois

Université de Tours

Département de Psychologie, EA 2114,

3, rue des Tanneurs - BP 4103, F-37041 Tours Cedex 1

Tél. : +33 (0) 247366685

Fax: +33 (0) 247366484

Email: robert.courtois@univ-tours.fr

Number of words: 6264 (3490 excluding references, figures, tables and abstracts).

Conflicts of interest: none

Funding: This research did not receive any specific grant from funding agencies in the public, commercial, or not-for-profit sectors. 


\begin{abstract}
Background: Fibromyalgia, rheumatoid arthritis, spondyloarthritis and Sjögren's syndrome are chronic rheumatic diseases with very different clinical characteristics, but which share symptoms such as pain and fatigue. The aim of the study was to examine the impact of the disease on psychological adaptation in fibromyalgia compared to other rheumatic diseases (rheumatoid arthritis, spondyloarthritis and Sjögren's syndrome).
\end{abstract}

Method: In a multicenter study, 165 women with rheumatic diseases (48 with fibromyalgia, 47 with rheumatoid arthritis, 47 with spondyloarthritis, 23 with Sjögren's syndrome) completed the GHQ-28 (emotional distress), FSS (fatigue), FIQ (impact of the disease), CSQ (coping), and MINI (comorbidity with DSM IV axis-I disorders). We used the Kruskal-Wallis test, MannWhitney U-test and the $\mathrm{Chi}^{2}$ test to compare comorbid anxiety and depressive disorders, and to compare the impact of the disease on patients' mental well-being and daily life and adjustment (coping strategies).

Results: Anxiety and depressive disorders were more common in fibromyalgia patients; they had higher scores on impact of the disease, physical symptoms, pain and fatigue than rheumatoid arthritis patients, and reported more fatigue than patients with spondyloarthritis. Overall, they used more maladaptive coping strategies (less use of Distancing from pain than patients with rheumatoid arthritis and spondyloarthritis, less use of Ignoring pain sensations, and more use of Catastrophizing than those with rheumatoid arthritis). No differences were found between fibromyalgia and Sjögren's syndrome on impact and adjustment.

Conclusions: Compared to other rheumatic diseases, fibromyalgia has a greater impact on daily life; patients have more difficulty adjusting to the disease and generally use poorer strategies to cope with pain.

Keywords: Fibromyalgia, rheumatic diseases, impact of the disease, psychological adjustment, coping, rheumatic diseases. 


\section{Introduction}

Fibromyalgia, rheumatoid arthritis, spondyloarthritis and Sjögren's syndrome are chronic diseases with different clinical characteristics, but which share symptoms such as pain and fatigue. Unlike the other three rheumatic diseases, which are clearly recognizable by their clinical, imaging and biological features, fibromyalgia is a diagnosis of exclusion, which can only be established once other conditions have been ruled out and could affect the way that patients cope and adjust to the disease. All these diseases have a major impact on patients' daily life, requiring considerable effort to cope with the illness. As most existing studies comparing fibromyalgia with other rheumatic diseases only consider it when it is associated with another rheumatic disease, they do not allow a clear distinction to be made between how patients adjust psychologically to each disease.

Studies have examined symptoms of fibromyalgia in inflammatory or autoimmune rheumatic diseases and the relationship with disease activity $(1,2)$. Other studies found that fibromyalgia patients had higher pain scores $(3,4)$ and greater fatigue variability (5) than patients with rheumatoid arthritis. Pain in rheumatoid arthritis is associated with depression, while in fibromyalgia, it is linked more to stress levels (6). Hence, pain and fatigue levels seem to be predictors of depression in rheumatoid arthritis, whereas distress markers are predictors of fibromyalgia (7). Patients with fibromyalgia reported more depressive episodes and anxiety disorders (panic disorder, post-traumatic stress disorder) than patients with rheumatoid arthritis $(8,9)$, and had higher scores on emotional distress, depression, anxiety and stress $(10,11)$. Patients with spondyloarthritis perceived a change in their daily life due to physical disability, while patients with fibromyalgia experienced these changes due to pain, anxiety, fatigue and disability (12). Finally, patients with fibromyalgia express lower general well-being than those with spondyloarthritis. They also report a poorer quality of life than patients with Sjögren's syndrome (particularly social and physical dimensions) (13). So far, no study has compared 
these diseases in terms of coping strategies. The aim of this study was to compare fibromyalgia, rheumatoid arthritis, spondyloarthritis and Sjögren's syndrome regarding (i) their impact on daily life, and (ii) psychological adjustment (coping strategies).

\section{Material and method}

\section{Participants}

The inclusion criteria were: a) women aged over 18 and under 70 years; b) duration of disease between 6 months and 10 years; c) social security cover; d) no difficulty communicating in French, and e) to have been informed about the study by her doctor. A rheumatologist systematically confirmed the diagnosis using international disease classification criteria: ACR (14) and FIRST criteria (15) for fibromyalgia; ACR criteria for rheumatoid arthritis (16); ASAS criteria for spondyloarthritis (17); and Vitali et al.'s criteria (18) for Sjögren's syndrome. He also ensured that patients met the inclusion and exclusion criteria for the study. The exclusion criteria were: association with another rheumatic diseases, HIV infection, history of cancer or blood malignancy, thyroid dysfunction and other endocrinopathies, viral hepatitis and all other comorbidities that the investigator considered to be severe (chronic heart failure, renal failure, respiratory failure, etc.).

\section{Measures}

To estimate the prevalence of anxiety and depressive disorders, we used the Mini International Neuropsychiatric Interview (MINI) (19, 20). This is a structured diagnostic interview exploring the presence or absence of the main DSM-IV axis-I disorders. It indicates comorbid anxiety and depressive disorders.

First, to assess the emotional distress caused by the disease, we used the General Health Questionnaire (GHQ) $(21,22)$. This is a self-administered questionnaire evaluating the level of 
distress experienced by the individual using a 4-point Likert scale. Its 28-item version investigates four areas of subjective emotional distress: Somatic symptoms, Anxiety-insomnia, Social dysfunction, Severe depression.

To assess the impact of the illness on daily life, first we used the Fibromyalgia Impact Questionnaire (FIQ) $(23,24)$, which is a self-administered questionnaire with 10 items assessing the physical, psychological and social impact of the illness on the quality of the patient's daily life using an 11-point Likert scale. Although this questionnaire is designed specifically for fibromyalgia, we assumed that it would be relevant for comparison of fibromyalgia with other diseases in these aspects. Secondly, to assess the common somatic symptoms of the disease in daily life, we used the Visual Analogic Scale (VAS), which assesses the level of pain on a scale of 0 to 10, and the Fatigue Severity Scale (FSS) (25), a selfadministered 9-item questionnaire assessing the level of fatigue and its functional consequences using a 7-point Likert scale.

Finally, to assess how patients adjust to living with a rheumatic disease, we used the Coping Strategies Questionnaire (CSQ) (26, 27), a 21-item self-administered questionnaire assessing five specific cognitive strategies of coping with pain: Distraction (thinking of things that can divert attention from pain), Catastrophizing (worrying and focusing only on the negative aspects of pain), Praying (saying to yourself that you have to hope and pray that the pain will one day go away), Distancing from pain (trying to perceive sensations other than pain), and Ignoring pain sensations (denying that pain makes us suffer and affects us). Usually, problem-focused coping strategies (Distancing from pain, Ignoring pain sensations) are better for health outcomes, while emotion-focused strategies (avoidant coping: Distraction, Catastrophizing, Praying) are less favorable.

\section{Procedure}


The data were collected in three French hospitals (Tours, Orleans and Paris) by a rheumatologist and a psychologist. Informed written consent was obtained from all the participants and an ethics committee approved the study.

\section{Data analysis}

Internal consistency of all the questionnaires was good, with a Cronbach's alpha coefficient $>.70$. As the variables were not normally distributed in each group, we used nonparametric analysis techniques. First, we compared comorbid anxiety and depressive disorders in fibromyalgia and the other rheumatic diseases (rheumatoid arthritis, spondyloarthritis and Sjögren's syndrome). To this end, we used the $\mathrm{Chi}^{2}$ test for categorical variables or Fisher's exact test when there were fewer than five subjects in a sample. Next, we conducted a KruskalWallis test (one-way ANOVA on ranks) to compare the impact of the disease on daily life and psychological adjustment in the different rheumatic diseases. After that, we performed a MannWhitney U test to compare fibromyalgia with the other diseases for continuous variables. We also conducted a hierarchical cluster analysis using Ward's linkage method with squared Euclidian distance, followed by a k-means cluster analysis, which allocates each case to the cluster with the nearest center point. To compare clusters, we used the Kruskal-Wallis test (including a pairwise post-hoc test). Statistical analyses were performed with Statistica ${ }^{\circledR}$ version 12.

\section{Results}

\section{Participants' characteristics}

The sample comprised 165 French women with rheumatic diseases, mean age 47.24 years $( \pm$ 10.77 years, range 21 to 65 ), with 4 sub-groups: 48 women with fibromyalgia (Mean age = $47.98 \pm 9.69$, range 25 to 65 ), 47 with rheumatoid arthritis (Mean age $=50.89 \pm 11.31$, range 
24 to 65 ), 47 with spondyloarthritis (Mean age $=42.30 \pm 9.30$, range 21 to 59), and 23 with Sjögren's syndrome (Mean age $=48.30 \pm 11.48$, range 25 to 64 ). There was a significant difference in age across groups $(\mathrm{H}(3,165)=16.88, p<.001)$. The average education level corresponded to completion of high school, with no significant difference between groups. Average duration of disease was 4.13 years ( \pm 2.83 , range .5 to 10$)$ with significant differences between groups $(\mathrm{H}(3,165)=9.40, p<.05)$. However, the effects of age and duration of disease were small and limited and indicated only a tendency towards a slight decrease of the functional repercussions with the evolution of the disease and the age of the patient (data not shown). Forty percent of the women were menopausal (35\% with fibromyalgia, $49 \%$ with rheumatoid arthritis, $26 \%$ with spondyloarthritis, and $61 \%$ with Sjögren's syndrome), with significant differences between groups $\left(\mathrm{Chi}^{2}=10.26, p<.05\right)$. For patients with fibromyalgia, the FIRST criterion mean was $5.92( \pm .28$, range 5 to 6$)$ and tender points mean was 16.79 ( \pm 2.30 , range 11 to 18$)$.

\section{Internal consistency}

The internal consistency of all scales was evaluated for each rheumatic disease. Cronbach's alpha coefficients were acceptable (between .69 and .94), as shown in Table 1. Descriptive data are provided in Table 2.

Please Insert Tables 1 and 2 here

\section{Comparison of the prevalence of anxiety and depressive disorders in patients with fibromyalgia and other rheumatic diseases}

Psychiatric disorders were assessed with the MINI in order to establish the prevalence of comorbidities. Tables 3 and 4 show only significant results in the comparison of comorbid anxiety and depressive disorders in fibromyalgia and the other rheumatic diseases. Fibromyalgia patients had experienced more recurrent (past) major depressive episodes than those with other diseases (rheumatoid arthritis, spondyloarthritis or Sjögren's syndrome). 
Anxiety disorders (agoraphobia and generalized anxiety disorder) were more common in fibromyalgia than in spondyloarthritis or Sjögren's syndrome; post-traumatic stress disorder was more common in fibromyalgia than in rheumatoid arthritis.

All analyses were then processed with menopausal and premenopausal women separately. Menopausal women with fibromyalgia presented with significantly more depressive disorders than those with other disorders, with the exception of menopausal women with spondyloarthritis who presented with more major depressive episodes with melancholic features. For premenopausal women, only the results for recurrent major depressive episodes were significant. There was a greater prevalence of current generalized anxiety disorder among premenopausal women with fibromyalgia than among those with other rheumatic diseases. This was the same for menopausal women, except in comparison with Sjögren's syndrome. There was a higher prevalence of agoraphobia among premenopausal women with fibromyalgia than among those with rheumatoid arthritis or spondyloarthritis. There was a higher prevalence of agoraphobia among, menopausal women with fibromyalgia than among those with Sjögren's syndrome.

Please Insert Tables 3 and 4 here

\section{Comparison of the impact of the disease and the coping strategies used by patients with fibromyalgia and other rheumatic diseases}

First, we observed overall effects. The ANOVA revealed significant differences between groups in the impact of the disease on daily life $(\mathrm{H}(3,165)=13.42, p<.05)$, Somatic symptoms $(\mathrm{H}(3,165)=11.64, p<.01)$, fatigue $(\mathrm{H}(3,165)=36.00, p<.001)$, and on the coping strategies of Distancing from pain $(\mathrm{H}(3,165)=10.75, p<.05)$ and Ignoring pain sensation $(\mathrm{H}$ $(3,165)=12.76, p<.01)$. Next, we performed a Mann-Whitney U-test to compare fibromyalgia with each of the other rheumatic diseases. Table 5 shows the results of comparative analyses 
for emotional distress, impact of the disease, pain, fatigue, and coping strategies. Patients with fibromyalgia had higher scores than those with rheumatoid arthritis for emotional distress (GHQ-28) (Somatic symptoms and Severe depression), for perceived fatigue, and impact of the disease. Patients with fibromyalgia were more likely to use a Catastrophizing strategy and less likely to use Distancing from pain and Ignoring pain sensation than patients with rheumatoid arthritis. They experienced greater pain, fatigue and more somatic symptoms and used the Ignoring pain sensations strategy less than patients with spondyloarthritis. There was no difference in the perception of the impact of the disease and in adjustment between fibromyalgia and Sjögren's syndrome patients.

\section{Please Insert Table 5 here}

Menopausal women with fibromyalgia reported a significantly greater impact of disease, pain and fatigue than those with rheumatoid arthritis, greater fatigue and less Distancing from pain than spondyloarthritis patients, and greater Distraction and Ignoring pain sensations than Sjögren's syndrome patients. Premenopausal women with fibromyalgia reported more Somatic symptoms and fatigue than those with rheumatoid arthritis and more fatigue than those with spondyloarthritis. Menopausal women seemed to be more affected by the disease, pain and fatigue than premenopausal women, but comparisons between the two groups were not significant (available on supplementary data).

\section{Major depressive episodes and emotional distress}

In order to examine the relationship between major depressive episodes (MDE) diagnosed with the MINI, emotional suffering evaluated by the General Health Questionnaire (GHQ), and pain or the strategies for coping with pain, we first investigated the functional impact of the presence or absence of current or recurrent MDE (Table 6). Next, we conducted a k-means cluster analysis. A three-cluster solution seems to reflect the particularities of each 
group while remaining easy to interpret (Figure 1). Cluster 1 was characterized by an absence of mood disorder (current or past MDE) and low or moderate scores on Severe depression, Anxiety/insomnia, Somatic symptoms and Social dysfunction. Cluster 2 included patients presenting with mood disorders (current and past MDE) and high scores on GHQ subscales. Patients in Cluster 3 had a past MDE, no current MDE, and moderate scores on GHQ subscales.

Please Insert Table 6, Figure 1 and 2 here

Cluster 1 was composed of 79 women (mean age $46.30 \pm 11.24$ years, range 23-65) with the highest rate of professional activity $\left(86 \%\right.$; $\mathrm{Chi}^{2}$ test, $\left.p<.01\right)$, and the lowest invalidity rate $(8 \%, \mathrm{~ns})$. It included 8 fibromyalgia patients (10.1\%), 27 rheumatoid arthritis patients $(34.2 \%)$, 31 spondyloarthritis patients (39.2\%), and 13 Sjögren's syndrome patients (16.5\%). Cluster 2 was composed of 51 women (mean age $48.43 \pm 9.26$ years, range $28-65$ years) with the lowest rate of professional activity (63\%), and the highest invalidity rate (22\%). It included 23 fibromyalgia patients (45.1\%), 8 rheumatoid arthritis patients (15.7\%), 13 spondyloarthritis patients $(25.5 \%)$ and 7 Sjögren's syndrome patients $(13.7 \%)$. Cluster $3(\mathrm{n}=34)$ was intermediate between Clusters 1 and 2, comprising patients with a mean age of $47.88 \pm 11.95$ years (range 21-65 years), $79 \%$ in professional activity, and an invalidity rate of $15 \%$. It comprised 17 fibromyalgia patients (50.0\% of the group), 11 rheumatoid arthritis patients (32.4\%), 3 spondyloarthritis patients (8.8\%) and 3 Sjögren's syndrome patients (8.8\%). The clinical characteristics of patients in Cluster 1 were also better than those in Cluster 2, while those of Cluster 3 were between the two (See Figure 2). Significant differences on KruskalWallis tests are indicated in the figure, and we also performed pairwise post-hoc tests to assess the differences between groups (group interactions).

Most fibromyalgia patients were included in the second (47.9\%) or third $(35.4 \%)$ cluster, with only $16.7 \%$ in the first. The majority of rheumatoid arthritis patients were in the 
first cluster (58.7\%) (vs $17.4 \%$ and $23.9 \%$ in Clusters 2 and 3 respectively). The situation was similar for both spondyloarthritis patients $(66.0 \%$ in Cluster 1 vs $27.7 \%$ in Cluster 2 and $6.4 \%$ in Cluster 3) and Sjögren's syndrome patients $(56.5 \%, 30.4 \%$, and 13.0\% in Clusters 1, 2 and 3 respectively).

\section{Discussion}

Consistent with previous studies (2-5), patients with fibromyalgia showed higher levels of pain, fatigue, perceived emotional distress, anxiety and depressive comorbidity (with a significant suicidal risk), and they made less use of the strategies of pain distancing and ignoring pain than patients with other rheumatic diseases.

In fibromyalgia, levels of pain and fatigue are markers of distress (7), and fatigue is associated with a reduction in positive affectivity, which plays a role in reducing the impact of pain (28). Symptoms of anxiety and depression in fibromyalgia are linked to physical symptomatology and functional disability and to an increase in pain and tender points (29-31). Depression appears to be fairly reactive to fibromyalgia (32) and the pain experienced by patients increases the risk of a major depressive episode (33). There is a significant bilateral causal link between depression and pain: pain depresses the patient and depression promotes pain (34-36). In this study, the emotional distress of fibromyalgia patients was associated with social dysfunction and somatic symptoms, and patients experienced more comorbid anxiety and depressive disorders, especially recurrent major depressive episodes and agoraphobia, than patients with other rheumatic diseases. The greater anxiety (agoraphobia, post-traumatic stress disorder and generalized anxiety disorder) and higher incidence of depressive disorders (major depressive episodes) could partly explain why fibromyalgia patients feel more affected by their illness in daily life than patients with other rheumatic diseases and could play a role in the way they adjust to the condition. Maladaptive coping strategies also contribute to the strengthening 
of mood disorders (e.g. 33, 37, 38). In this study, the comparative table with and without MDE (current or past MDE) and the nonhierarchical cluster analysis highlight the importance of mood disorders in fibromyalgia patients and their association with levels of pain, fatigue and maladaptive coping strategies. Our results also show the importance of checking for past MDEs due to their association with emotional distress. They can be indicators of the vulnerability of patients, but it is difficult to establish whether the functional repercussions are the result of mood disorders or represent aspects of behavior that are closely related to fibromyalgia.

In the present study, fibromyalgia patients used Catastrophizing more than patients with rheumatoid arthritis, Distancing from pain less than patients with rheumatoid arthritis, and Ignoring pain sensations less than patients with rheumatoid arthritis and spondyloarthritis. Patients with fibromyalgia rarely use active coping strategies to improve their quality of life (39) and are more likely to resort to maladaptive coping strategies than patients with other rheumatic diseases. The use of maladaptive strategies is an indication of how patients give up trying to manage pain or assign this responsibility to an outside source (34). Catastrophizing is linked to the intensity of pain and the severity of depression, which are markers of maladjustment $(34,40)$.

The comparison between fibromyalgia and rheumatoid arthritis shows that fibromyalgia patients feel the effects of the disease more strongly (higher level of pain, fatigue and impact of illness on daily life) and present with more anxious and depressive disorders, fewer adaptive coping strategies, and more catastrophizing than patients with rheumatoid arthritis. Rheumatoid arthritis is considered as the archetype of rheumatic diseases and is easier to diagnose than fibromyalgia. The lack of objective diagnostic criteria for fibromyalgia can often lead patients to consult multiple practitioners before the diagnosis is considered. This doctor shopping (or "medical nomadism") results in multiple and often conflicting opinions, which may give patients a sense of being misunderstood and of injustice, that they are given no support or 
consideration for their suffering, and fear about their future (41-43). This would in turn lead to an increase in emotional insecurity (44) and a lack of understanding of their physical state, resulting in an inability to cope with the disease on a daily basis and heightened anxiety and depressive disorders.

This acute perception by patients of the effects of fibromyalgia on their daily life and their poor use of coping strategies could also be seen in connection with personality, which plays an essential role in how we interpret our environment (health beliefs and underlying dysfunctional thoughts), notably Neuroticism, which is the tendency to perceive reality as threatening and painful and is connected with psychological distress and mood disorders. Neuroticism has been shown to be higher in fibromyalgia patients than in those with other rheumatic diseases (45) and could explain the greater presence of depression in fibromyalgia.

There was no difference between fibromyalgia and Sjögren's syndrome patients in the way they perceived the impact of their illness on their daily life, and in the use of coping strategies. This could be explained by the difficulty of establishing a diagnosis in both these diseases, often delayed for several years because of the variability of the clinical features and the insidious progress of Sjögren's syndrome and the lack of objective diagnostic criteria for Fibromyalgia, which often leads to loss of confidence, discouragement and feelings of uncertainty about the future. Although these diseases differ in severity, prognosis and treatment, it appears that the difficulty of making a diagnosis could have a negative impact on how patients cope and adjust to the disease.

Menopausal women accounted for $40 \%$ of our sample. Overall, they presented with more depressive disorders than premenopausal women, but the differences were not statistically significant. It is widely accepted that menopausal transition may affect women and increase the risk of mood disorders (e.g. 46), but other factors must be taken into account, such as age, duration of the disease, somatic symptoms, type of rheumatic disease, etc. While the menopause 
can interact with anxiety or pain, it can also accentuate the phenomena of dryness of the mouth and vagina, which cause the patient real discomfort, particularly in Sjögren's syndrome; as these symptoms can be difficult to talk about, they may not be adequately treated. Menopause should be systematically included in the medical monitoring of rheumatic diseases.

The limitations of the study are mainly related to the self-assessment of the impact of the illness on daily life and coping strategies and the sample size. The subgroup of Sjögren's syndrome patients was small (it is a much rarer disease) and the inclusion and exclusion criteria restricted the number of participants.

\section{Conclusion}

This study shows that patients with fibromyalgia have higher levels of pain, greater incidence of anxiety, somatic symptoms and depressive disorders, and a worse quality of life than patients with other rheumatic diseases. It also shows that patients with fibromyalgia have greater difficulty adjusting to the illness, with significant consequences on outcome. Helping patients develop appropriate coping strategies should be part of the management of rheumatic diseases, particularly fibromyalgia and Sjögren's syndrome. It would be desirable for rheumatology departments to have a psychologist on their staff to systematically check for any history of mood disorders (due to their association with levels of pain, fatigue and maladaptive coping strategies) and more generally, to assess how patients adapt to their disease.

\section{Acknowledgments:}

We would like to thank Dr Odile Plaisant, Professor Pierre Bourgeois and Professor Bruno Fautrel (Assistance Publique - Hôpitaux de Paris, University Hospital of PitiéSalpêtrière) and Dr Stéphanie Rist and Dr Carine Salliot (Regional Hospital of Orléans) for their involvement in selecting the patients and the quality of data collection. 


\section{References}

1. El-Rabbat MS, Mahmoud NK, Gheita TA. Clinical significance of fibromyalgia syndrome in different rheumatic diseases: Relation to disease activity and quality of life. Reumatol Clin. 2017.

2. Haliloglu S, Carlioglu A, Akdeniz D, Karaaslan Y, Kosar A. Fibromyalgia in patients with other rheumatic diseases: prevalence and relationship with disease activity. Rheumatol Int. 2014;34(9):1275-80.

3. Laursen BS, Bajaj P, Olesen AS, Delmar C, Arendt-Nielsen L. Health related quality of life and quantitative pain measurement in females with chronic non-malignant pain. Eur $\mathrm{J}$ Pain. 2005;9(3):267-75.

4. Tander B, Cengiz K, Alayli G, Ilhanli I, Canbaz S, Canturk F. A comparative evaluation of health related quality of life and depression in patients with fibromyalgia syndrome and rheumatoid arthritis. Rheumatol Int. 2008;28(9):859-65.

5. Zautra AJ, Fasman R, Parish BP, Davis MC. Daily fatigue in women with osteoarthritis, rheumatoid arthritis, and fibromyalgia. Pain. 2007;128(1-2):128-35.

6. Drummond PD, Willox M. Painful effects of auditory startle, forehead cooling and psychological stress in patients with fibromyalgia or rheumatoid arthritis. J Psychosom Res. 2013;74(5):378-83.

7. Wolfe F, Michaud K. Predicting depression in rheumatoid arthritis: The signal importance of pain extent and fatigue, and comorbidity. Arthritis Care Res. 2009;61(5):667-73.

8. El-Hage W, Lamy C, Goupille P, Gaillard P, Camus V. Fibromyalgie : une maladie du traumatisme psychique? Press Med. 2006;35(11):1683-9.

9. Patten SB, Williams JVA, Wang JL. Mental disorders in a population sample with musculoskeletal disorders. BMC Musculoskel Disord. 2006;7:37.

10. Arnold LM, Hudson JI, Keck PE, Auchenbach MB, Javaras KN, Hess EV. Comorbidity of fibromyalgia and psychiatric disorders. J Clin Psychiatr. 2006;67(8):1219-25.

11. Sayar K, Gulec H, Topbas M. Alexithymia and anger in patients with fibromyalgia. Clin Rheumatol. 2004;23(5):441- 8.

12. Ovayolu N, Ovayolu O, Karadag G. Health-related quality of life in ankylosing spondylitis, fibromyalgia syndrome, and rheumatoid arthritis: a comparison with a selected sample of healthy individuals. Clin Rheumatol. 2011;30(5):655-64.

13. Hincapie-Zapata ME, Suarez-Escudero JC, Pineda-Tamayo R, Anaya JM. [Quality of life in multiple sclerosis and other chronic autoimmune and non-autoimmune diseases]. Rev Neurol. 2008;48(5):225-30.

14. Wolfe F, Smythe HA, Yunus MB, Bennett RM, Bombardier C, Goldenberg DL, et al. The american college of rheumatology 1990 criteria for the classification of fibromyalgia. Arthritis Rheum. 1990;33(2):160-72. 
15. Perrot S, Bouhassira D, Fermanian J. Development and validation of the Fibromyalgia Rapid Screening Tool (FiRST). Pain. 2010;150(2):250-6.

16. Arnett FC, Edworthy SM, Bloch DA, McShane DJ, Fries JF, Cooper NS, et al. The american rheumatism association 1987 revised criteria for the classification of rheumatoid arthritis. Arthritis Rheum. 1988;31(3):315-24.

17. Rudwaleit M, Landewé R, van der Heijde D, Listing J, Brandt J, Braun J, et al. The development of Assessment of SpondyloArthritis international Society classification criteria for axial spondyloarthritis (part I): classification of paper patients by expert opinion including uncertainty appraisal. Ann Rheum Dis. 2009;68(6):770-6.

18. Vitali C, Bombardieri S, Jonsson R, Moutsopoulos HM, Alexander EL, Carsons SE, et al. Classification criteria for Sjögren's syndrome: a revised version of the European criteria proposed by the American-European Consensus Group. Ann Rheum Dis. 2002;61(6):554-8.

19. Sheehan DV, Lecrubier Y, Sheehan KH, Amorim P, Janavs J, Weiller E, et al. The MiniInternational Neuropsychiatric Interview (M.I.N.I.): The development and validation of a structured diagnostic psychiatric interview for DSM-IV and ICD-10 J Clin Psychiatr. 1998;59:22-33.

20. Lecrubier Y, Weiller E, Hergueta T, Amorim P, Bonora LI, Lépine JP. Mini International Neuropsychiatric Interview French Version 5.0. 0. Paris, France: INSERM; 1998.

21. Goldberg DP, Williams P. A user's guide to the General Health Questionnaire. Windsor, United Kingdom: Nfer-Nelson; 1988.

22. Pariente PD, Challita H, Mesbah M, Guelfi JD. The GHQ-28 questionnaire in French: A validation survey in a panel of 158 general psychiatric patients. Eur Psychiatry. 1992;7(1):15-20.

23. Burckhardt CS, Clark SR, Bennett RM. The fibromyalgia impact questionnaire: development and validation. J Rheumatol. 1991;18(5):728-33.

24. Perrot S, Dumont D, Guillemin F, Pouchot J, Coste J, French Group for Quality of Life R. Quality of life in women with fibromyalgia syndrome: validation of the QIF, the French version of the fibromyalgia impact questionnaire. $\mathrm{J}$ Rheumatol. 2003;30(5):1054-9.

25. Krupp LB, LaRocca NG, Muir-Nash J, Steinberg AD. The fatigue severity scale: application to patients with multiple sclerosis and systemic lupus erythematosus. Arch Neurol. 1989;46(10):1121-3.

26. Rosenstiel AK, Keefe FJ. The use of coping strategies in chronic low back pain patients: relationship to patient characteristics and current adjustment. Pain. 1983;17(1):33-44.

27. Irachabal S, Koleck M, Rascle N, Bruchon-Schweitzer M. Stratégies de coping des patients douloureux : adaptation française du coping strategies questionnaire (CSQ-F). Encephale. 2008;34(1):47-53. 
28. Zautra AJ, Smith BW. Depression and Reactivity to Stress in Older Women With Rheumatoid Arthritis and Osteoarthritis. Psychosom Med. 2001;63:687-96.

29. Homann D, Stefanello JMF, Góes SM, Breda CA, Paiva EdS, Leite N. Percepção de estresse e sintomas depressivos: funcionalidade e impacto na qualidade de vida em mulheres com fibromialgia. Rev Bras Reumatol. 2012;52:324-30.

30. Thieme K, Turk DC, Flor H. Comorbid depression and anxiety in fibromyalgia syndrome: relationship to somatic and psychosocial variables. Psychosom Med. 2004;66(6):83744.

31. Aguglia A, Salvi V, Maina G, Rossetto I, Aguglia E. Fibromyalgia syndrome and depressive symptoms: Comorbidity and clinical correlates. J Affect Disord. 2011;128(3):262-6.

32. White KP, Nielson W, Harth M, Ostbye T, Speechley M. Chronic widespread musculoskeletal pain with or without fibromyalgia: psychological distress in a representative community adult sample. J Rheumatol. 2002;29(3):588-94.

33. Raphael KG, Janal MN, Nayak S, Schwartz JE, Gallagher RM. Psychiatric comorbidities in a community sample of women with fibromyalgia. Pain. 2006;124(1-2):117-25.

34. Radat F, Koleck M. [Pain and depression: cognitive and behavioural mediators of a frequent association]. Encephale. 2011;37(3):172-9.

35. Wessely S, Hindmarch I. Taking the pain out of depression: Dual action antidepressants in the relief of pain in depression, fibromyalgia and other chronic pain syndromes. Hum Psychopharmacol Clin Exp. 2004;19(Suppl1):S1-S2.

36. Williams LJ, Jacka FN, Pasco JA, Dodd S, Berk M. Depression and pain: an overview. Acta Neuropsychiatrica. 2006;18(2):79-87.

37. Garnefski N, Legerstee J, Kraaij V, Van Den Kommer T, Teerds JAN. Cognitive coping strategies and symptoms of depression and anxiety: a comparison between adolescents and adults. J Adolesc. 2002;25(6):603-11.

38. Hudson JI, Goldenberg DL, Pope Jr HG, Keck Jr PE, Schlesinger L. Comorbidity of fibromyalgia with medical and psychiatric disorders. Am J Med. 1992;92(4):363-7.

39. Theadom A, Cropley M, Humphrey KL. Exploring the role of sleep and coping in quality of life in fibromyalgia. J Psychosom Res. 2007;62(2):145- 51.

40. Edwards RR, Cahalan C, Mensing G, Smith M, Haythornthwaite JA. Pain, catastrophizing, and depression in the rheumatic diseases. Nat Rev Rheumatol. 2011;7(4):216-24.

41. Ferrari R, Russell AS. Perceived injustice in fibromyalgia and rheumatoid arthritis. Clin Rheumatol. 2014;33(10):1501-7.

42. Laroche F, Guérin J, Azoulay D, Coste J, Perrot S. La fibromyalgie en France : vécu quotidien, fardeau professionnel et prise en charge. Enquête nationale auprès de 4516 patients. Rev Rhum. 2018. 
43. Sullivan MJL, Adams H, Horan S, Maher D, Boland D, Gross R. The Role of Perceived Injustice in the Experience of Chronic Pain and Disability: Scale Development and Validation. J Occup Rehabil. 2008;18(3):249-61.

44. van Houdenhove B. Prevalence and Psychodynamic Interpretation of Premorbid Hyperactivity in Patients with Chronic Pain. Psychother Psychosom. 1986;45(4):195200.

45. Bucourt E, Martaille V, Mulleman D, Goupille P, Joncker-Vannier I, Huttenberger B, et al. Comparison of the Big Five personality traits in fibromyalgia and other rheumatic diseases. Joint Bone Spine. 2017;84(2):203-7.

46. Cohen LS, Soares CN, Vitonis AF, Otto MW, Harlow BL. Risk for new onset of depression during the menopausal transition: The harvard study of moods and cycles. Arch Gen Psychiatry. 2006;63(4):385-90. 


\begin{tabular}{lccccc}
\hline & AR & FM & RA & SpA & SS \\
\cline { 2 - 5 } Psychic suffering (GHQ) & .93 & .92 & .93 & .92 & .94 \\
- Somatic symptoms & .80 & .75 & .74 & .84 & .80 \\
- Anxiety/insomnia & .84 & .82 & .90 & .77 & .87 \\
- Social dysfunction & .84 & .83 & .84 & .81 & .89 \\
- Severe depression & .90 & .91 & .90 & .90 & .88 \\
Impact of disease (FIQ) & .84 & .71 & .84 & .86 & .86 \\
Fatigue (FSS) & .92 & .85 & .93 & .91 & .94 \\
Coping strategy (CSQ) & .90 & .89 & .92 & .88 & .91 \\
- Distraction & .84 & .84 & .85 & .82 & .86 \\
- Praying & .85 & .69 & .94 & .87 & .94 \\
- Distancing from pain & .91 & .90 & .89 & .93 & .90 \\
- Ignoring pain sensations & .90 & .86 & .91 & .85 & .92 \\
- Catastrophizing & .88 & .91 & .87 & .89 & .85 \\
\end{tabular}

GHQ: General Health questionnaire; FIQ: Fibromyalgia Impact Questionnaire; FSS: Fatigue Severity Scale; CSQ: Coping Strategies Questionnaire; AR: all rheumatic diseases. FM:

fibromyalgia; RA: rheumatoid arthritis; SpA: spondyloarthritis; SS: Sjögren's syndrome. 


\begin{tabular}{|c|c|c|c|c|c|}
\hline & $\begin{array}{c}\text { All rheumatic } \\
\text { diseases }\end{array}$ & $\mathrm{FM}$ & RA & SpA & $\mathrm{SS}$ \\
\hline Number & 165 & 48 & 47 & 47 & 23 \\
\hline Age, years & $47.24 \pm 10.77$ & $47.98 \pm 9.69$ & $50.89 \pm 11.31$ & $42.30 \pm 9.30$ & $48.3 \pm 11.48$ \\
\hline Mean disease duration (years) & $4.13 \pm 2.83$ & $3.54 \pm 2.76$ & $4.85 \pm 2.96$ & $4.50 \pm 2.81$ & $3.13 \pm 2.30$ \\
\hline Years of education & $12.15 \pm 2.55$ & $12.02 \pm 2.69$ & $11.98 \pm 2.63$ & $12.68 \pm 2.34$ & $11.70 \pm 2.51$ \\
\hline Professional activity (\%) & $.77 \pm .42$ & $.69 \pm .47$ & $.89 \pm .31$ & $.72 \pm .45$ & $.78 \pm .42$ \\
\hline Professional invalidity (\%) & $.13 \pm .34$ & $.25 \pm .44$ & $.11 \pm .31$ & $.06 \pm .25$ & $.09 \pm .29$ \\
\hline Menopause (\%) & $.40 \pm .49$ & $.35 \pm .48$ & $.49 \pm .51$ & $.26 \pm .44$ & $.61 \pm .50$ \\
\hline FIRST & NA & $5.92 \pm .28$ & NA & NA & NA \\
\hline Tender points & NA & $16.79 \pm 2.30$ & NA & NA & NA \\
\hline Anti-TNF treatment & NA & NA & $.68 \pm .47$ & $.74 \pm .44$ & NA \\
\hline Somatic symptoms (GHQ) & $9.38 \pm 4.48$ & $10.83 \pm 4.10$ & $7.72 \pm 3.96$ & $9.21 \pm 4.91$ & $10.04 \pm 4.43$ \\
\hline Anxiety/insomnia (GHQ) & $8.47 \pm 4.72$ & $9.10 \pm 4.63$ & $7.52 \pm 5.06$ & $8.19 \pm 4.12$ & $9.61 \pm 5.19$ \\
\hline Social dysfunction (GHQ) & $9.70 \pm 3.49$ & $10.17 \pm 3.55$ & $8.98 \pm 3.17$ & $9.70 \pm 3.46$ & $10.17 \pm 4.02$ \\
\hline Severe depression (GHQ) & $5.16 \pm 5.21$ & $6.13 \pm 5.61$ & $3.74 \pm 4.47$ & $5.13 \pm 5.08$ & $6.09 \pm 5.65$ \\
\hline Impact of disease (FIQ) & $51.44 \pm 17.45$ & $56.35 \pm 13.61$ & 43.0918 .95 & $52.91 \pm 17.00$ & $55.43 \pm 17.15$ \\
\hline Pain (VAS) & $6.18 \pm 2.69$ & $6.96 \pm 1.95$ & $5.26 \pm 3.22$ & $6.19 \pm 2.73$ & $6.43 \pm 2.31$ \\
\hline Fatigue (FSS) & $5.33 \pm 1.51$ & $6.13 \pm 1.07$ & $4.47 \pm 1.57$ & $5.17 \pm 1.44$ & $5.76 \pm 1.35$ \\
\hline Distraction (CSQ) & $11.35 \pm 4.32$ & $11.52 \pm 4.40$ & $11.96 \pm 4.47$ & $11.41 \pm 3.84$ & $9.65 \pm 4.57$ \\
\hline Praying(CSQ) & $4.50 \pm 3.47$ & $5.15 \pm 3.30$ & $4.62 \pm 3.64$ & $4.04 \pm 3.29$ & $3.83 \pm 3.75$ \\
\hline Distancing from pain (CSQ) & $6.02 \pm 4.15$ & $5.00 \pm 3.40$ & $7.47 \pm 4.62$ & $6.48 \pm 4.17$ & $4.26 \pm 3.48$ \\
\hline Ignoring pain sensations (CSQ) & $10.19 \pm 4.60$ & $9.15 \pm 4.08$ & $11.43 \pm 5.09$ & $11.13 \pm 3.82$ & $7.96 \pm 4.97$ \\
\hline Catastrophizing (CSQ) & $7.19 \pm 3.84$ & $8.10 \pm 4.06$ & $6.34 \pm 3.55$ & $7.30 \pm 4.10$ & $6.78 \pm 3.10$ \\
\hline
\end{tabular}

GHQ: General Health questionnaire; FIQ: Fibromyalgia Impact Questionnaire; FSS: Fatigue Severity Scale; CSQ: Coping Strategies Questionnaire; AR: all rheumatic diseases ; FM: fibromyalgia; RA: Rheumatoid Arthritis; SpA: Spondyloarthritis; SS: Sjögren's Syndrome. NA: not applicable 


\begin{tabular}{|c|c|c|c|c|c|}
\hline & & $\begin{array}{c}\mathrm{FM} \\
(\mathrm{n}, \%)\end{array}$ & $\begin{array}{c}\mathrm{RA} \\
(\mathrm{n}, \%)\end{array}$ & $\begin{array}{l}\mathrm{Chi}^{2} \\
\text { value }\end{array}$ & $\begin{array}{c}p \text { Chi }^{2} \text { (or Fisher's } \\
\text { exact when } \mathrm{n}<5 \text { ) }\end{array}$ \\
\hline \multirow[t]{2}{*}{ PD lifetime } & Abs. & $41(85.4 \%)$ & $47(100 \%)$ & & \\
\hline & Pres. & $7(14.6 \%)$ & $0(0 \%)$ & 7.40 & .012 \\
\hline \multirow[t]{2}{*}{ Agoraphobia } & Abs. & $29(60.4 \%)$ & $38(80.9 \%)$ & & \\
\hline & Pres. & $19(39.6 \%)$ & $9(19.1 \%)$ & 4.77 & .029 \\
\hline \multirow[t]{2}{*}{ PD with agoraphobia } & Abs. & $40(83.3 \%)$ & $46(97.9 \%)$ & & \\
\hline & Pres. & $8(16.7 \%)$ & $1(2.1 \%)$ & 5.85 & .031 \\
\hline \multirow[t]{2}{*}{ PTSD } & Abs. & $44(91.7 \%)$ & $47(100 \%)$ & & \\
\hline & Pres. & $4(8.3 \%)$ & $0(0 \%)$ & 4.09 & .043 \\
\hline \multirow[t]{3}{*}{ Current GAD } & Abs. & $29(60.4 \%)$ & $44(93.6 \%)$ & & \\
\hline & Pres. & $19(39.6 \%)$ & $3(6.4 \%)$ & 14.71 & .001 \\
\hline & & $\begin{array}{l}\text { FM } \\
(\mathrm{n}, \%)\end{array}$ & $\begin{array}{l}\mathrm{SpA} \\
(\mathrm{n}, \%)\end{array}$ & $\begin{array}{l}\text { chi }^{2} \\
\text { value }\end{array}$ & $\begin{array}{c}p \mathrm{Chi}^{2} \text { (or Fisher's } \\
\text { exact when } \mathrm{n}<5 \text { ) }\end{array}$ \\
\hline \multirow[t]{2}{*}{ Agoraphobia } & Abs. & $29(60.4 \%)$ & $40(85.1 \%)$ & & \\
\hline & Pres. & $19(39.6 \%)$ & $7(14.9 \%)$ & 7.28 & .011 \\
\hline \multirow[t]{3}{*}{ Current GAD } & Abs. & $29(60.4 \%)$ & $45(95.7 \%)$ & & \\
\hline & Pres. & $19(39.6 \%)$ & $2(4.3 \%)$ & 17.21 & .001 \\
\hline & & $\begin{array}{c}\mathrm{FM} \\
(\mathrm{n}, \%)\end{array}$ & $\begin{array}{c}\mathrm{SS} \\
(\mathrm{n}, \%)\end{array}$ & $\begin{array}{l}\mathrm{Chi}^{2} \\
\text { value }\end{array}$ & $\begin{array}{c}p \mathrm{Chi}^{2} \text { (or Fisher's } \\
\text { exact when } \mathrm{n}<5 \text { ) }\end{array}$ \\
\hline \multirow[t]{2}{*}{ Agoraphobia } & Abs. & $29(60.4 \%)$ & $21(91.3 \%)$ & & \\
\hline & Pres. & $19(39.6 \%)$ & $2(8.7 \%)$ & 7.12 & .011 \\
\hline \multirow[t]{2}{*}{ Current GAD } & Abs. & $29(60.4 \%)$ & $21(91.3 \%)$ & & \\
\hline & Pres. & $21(39.6 \%)$ & $2(8.7 \%)$ & 7.12 & .011 \\
\hline
\end{tabular}

Abs.: absence; Pres.: presence; PD: Panic Disorder; GAD: Generalized Anxiety Disorder; PTSD: Post-Traumatic Stress Disorder; FM: Fibromyalgia; RA: Rheumatoid Arthritis; SpA: Spondyloarthritis; SS: Sjögren's Syndrome. 


\begin{tabular}{|c|c|c|c|c|c|}
\hline & & $\begin{array}{c}\mathrm{FM} \\
(\mathrm{n}, \%)\end{array}$ & $\begin{array}{c}\mathrm{RA} \\
(\mathrm{n}, \%)\end{array}$ & $\begin{array}{l}\mathrm{Chi}^{2} \\
\text { value }\end{array}$ & $\begin{array}{c}p \mathrm{Chi}^{2} \text { (or Fisher's } \\
\text { exact when } \mathrm{n}<5 \text { ) }\end{array}$ \\
\hline \multirow[t]{2}{*}{ Current MDE } & Abs. & $25(52.1 \%)$ & $37(78.7 \%)$ & & \\
\hline & Pres. & $23(47.9 \%)$ & $10(21.3 \%)$ & 7.43 & .001 \\
\hline \multirow[t]{2}{*}{ Recurrent MDE } & Abs. & $14(29.2 \%)$ & $29(61.7 \%)$ & & \\
\hline & Pres. & $34(70.8 \%)$ & $18(38.3 \%)$ & 10.15 & .001 \\
\hline \multirow{2}{*}{$\begin{array}{l}\text { MDE with } \\
\text { melancholic features }\end{array}$} & Abs. & $39(81.3 \%)$ & $47(100 \%)$ & & \\
\hline & Pres. & $9(18.8 \%)$ & $0(0 \%)$ & 9.74 & .003 \\
\hline \multirow[t]{3}{*}{ Suicide risk } & Abs. & $35(72.9 \%)$ & $44(93.6 \%)$ & & \\
\hline & Pres. & $13(27.1 \%)$ & $3(6.4 \%)$ & 7.27 & .012 \\
\hline & & $\begin{array}{c}\text { FM } \\
(\mathrm{n}, \%)\end{array}$ & $\begin{array}{l}\mathrm{SpA} \\
(\mathrm{n}, \%)\end{array}$ & $\mathrm{Chi}^{2}$ value & $\begin{array}{c}p \mathrm{Chi}^{2} \text { (or Fisher's } \\
\text { exact when } \mathrm{n}<5 \text { ) }\end{array}$ \\
\hline \multirow[t]{3}{*}{ Recurrent MDE } & Abs. & $14(29.2 \%)$ & $36(76.6 \%)$ & & \\
\hline & Pres. & $34(70.8 \%)$ & $11(23.4 \%)$ & 21.43 & .001 \\
\hline & & $\begin{array}{c}\text { FM } \\
(\mathrm{n}, \%)\end{array}$ & $\begin{array}{c}\text { SS } \\
(\mathrm{n}, \%)\end{array}$ & $\mathrm{Chi}^{2}$ value & $\begin{array}{l}p \text { Chi }^{2} \text { (or Fisher's } \\
\text { exact when } \mathrm{n}<5 \text { ) }\end{array}$ \\
\hline \multirow[t]{2}{*}{ Recurrent MDE } & Abs. & $14(29.2 \%)$ & $18(78.3 \%)$ & & \\
\hline & Pres. & $34(70.8 \%)$ & $5(21.7 \%)$ & 15.14 & .001 \\
\hline \multirow{2}{*}{$\begin{array}{l}\text { MDE with } \\
\text { melancholic features }\end{array}$} & Abs. & $39(81.3 \%)$ & $23(100 \%)$ & & \\
\hline & Pres. & $9(18.8 \%)$ & $0(0 \%)$ & 7.12 & .011 \\
\hline
\end{tabular}

Abs.: absence; Pres.: presence; MDE: Major Depressive Episode; Recurrent MDE (MINI-V for past MDE); FM: Fibromyalgia; RA: Rheumatoid Arthritis; SpA: Spondyloarthritis; SS: Sjögren's Syndrome. 
Table 5: Results of significant comparative analyses of fibromyalgia and other rheumatic diseases

\begin{tabular}{lcccc}
\hline & Means FM & Means RA & $\mathrm{Z}$ & $p$ \\
\cline { 2 - 5 } Somatic symptoms (GHQ) & 10.83 & 7.72 & 3.30 & .001 \\
Severe depression (GHQ) & 6.13 & 3.74 & 2.22 & .026 \\
Impact of disease (FIQ) & 56.35 & 43.00 & 3.39 & .001 \\
Pain (VAS) & 6.96 & 5.26 & 2.49 & .001 \\
Fatigue (FSS) & 6.13 & 4.47 & 5.58 & .001 \\
Distancing from pain (CSQ) & 5.00 & 7.47 & -2.52 & .012 \\
Ignoring pain sensations (CSQ) & 9.15 & 11.43 & -2.44 & .015 \\
Catastrophizing (CSQ) & 8.10 & 6.34 & 2.40 & .016 \\
& & & & \\
\cline { 2 - 5 } & Means FM & Means SpA & $\mathrm{Z}$ & $p$ \\
\cline { 2 - 5 } Somatic symptoms (GHQ) & 10.83 & 9.21 & 1.96 & .050 \\
Fatigue (FSS) & 6.13 & 5.17 & 3.58 & .001 \\
Ignoring pain sensations & 9.15 & 11.13 & -2.18 & .030 \\
& & & &
\end{tabular}

FM: Fibromyalgia; RA: Rheumatoid Arthritis; SpA: Spondyloarthritis; GHQ: General Health questionnaire; FIQ: Fibromyalgia Impact Questionnaire; VAS: Visual Analogic Scale; FSS: Fatigue Severity Scale; CSQ: Coping Strategies Questionnaire 
Table 6: Impact of the presence or absence of depression on coping strategies and on daily health status

\begin{tabular}{|c|c|c|c|c|}
\hline & $\begin{array}{l}\text { Absence of } \\
\text { current MDE } \\
\text { (means) }\end{array}$ & $\begin{array}{l}\text { Presence of } \\
\text { current MDE } \\
\quad \text { (means) }\end{array}$ & $\mathrm{Z}$ & $p$ \\
\hline \multicolumn{5}{|l|}{ Psychic suffering: } \\
\hline - Somatic symptoms & 8.72 & 11.85 & -5.04 & .001 \\
\hline - Anxiety/insomnia & 7.15 & 11.17 & -4.99 & .001 \\
\hline - Social dysfunction & 8.78 & 11.57 & -4.80 & .001 \\
\hline - Severe depression & 3.15 & 9.26 & -6.74 & .001 \\
\hline Impact of disease & 46.24 & 62.13 & -5.69 & .001 \\
\hline Pain & 5.52 & 7.54 & -4.46 & .001 \\
\hline Fatigue & 4.92 & 6.18 & -5.18 & .001 \\
\hline \multicolumn{5}{|l|}{ Coping strategy: } \\
\hline - Distraction & 11.79 & 10.46 & 2.03 & .05 \\
\hline - Distancing from pain & 6.61 & 4.81 & 2.21 & .05 \\
\hline - Ignoring pain sensations & 10.94 & 8.67 & 3.20 & .01 \\
\hline \multirow[t]{2}{*}{ - Catastrophizing } & 6.48 & 8.63 & -2.73 & .01 \\
\hline & $\begin{array}{c}\text { Absence of } \\
\text { recurrent } \\
\text { MDE (means) }\end{array}$ & $\begin{array}{l}\text { Presence of } \\
\text { recurrent } \\
\text { MDE (means) }\end{array}$ & Z & $p$ \\
\hline \multicolumn{5}{|l|}{ Psychic suffering: } \\
\hline - Somatic symptoms & 8.42 & 10.78 & -3.63 & .001 \\
\hline - Anxiety/insomnia & 7.78 & 9.46 & -2.35 & .05 \\
\hline - Social dysfunction & 9.26 & 10.40 & -2.26 & .05 \\
\hline - Severe depression & 4.13 & 6.66 & -3.47 & .001 \\
\hline Impact of disease: & 48.00 & 56.35 & -2.98 & .01 \\
\hline Fatigue: & 4.94 & 5.89 & -3.70 & .001 \\
\hline \multicolumn{5}{|l|}{ Coping strategy: } \\
\hline - Catastrophizing & 6.41 & 8.31 & -2.79 & .01 \\
\hline
\end{tabular}

MDE: Major Depressive Episode; Recurrent MDE (MINI-V for past MDE). 


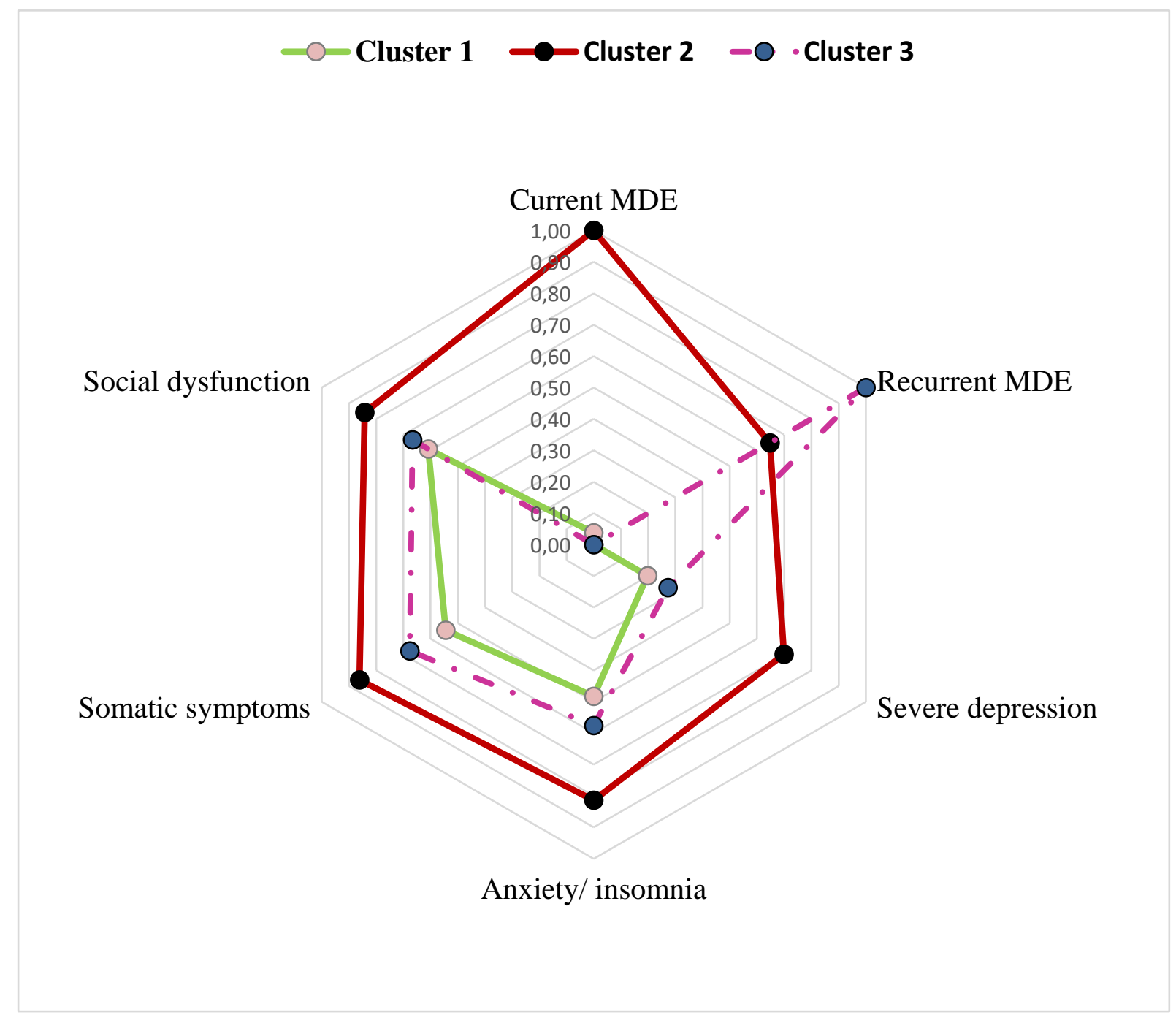

Current MDE (MINI); Recurrent MDE (MINI); Severe depression (GHQ); Anxiety/insomnia (GHQ); Somatic symptoms (GHQ); Social dysfunction (GHQ)

The scores of the GHQ subscales (which normally vary between 0 and 21) were divided by 14 to make them clearer in the figure.

Figure 1: Nonhierarchical cluster analysis of the whole sample 


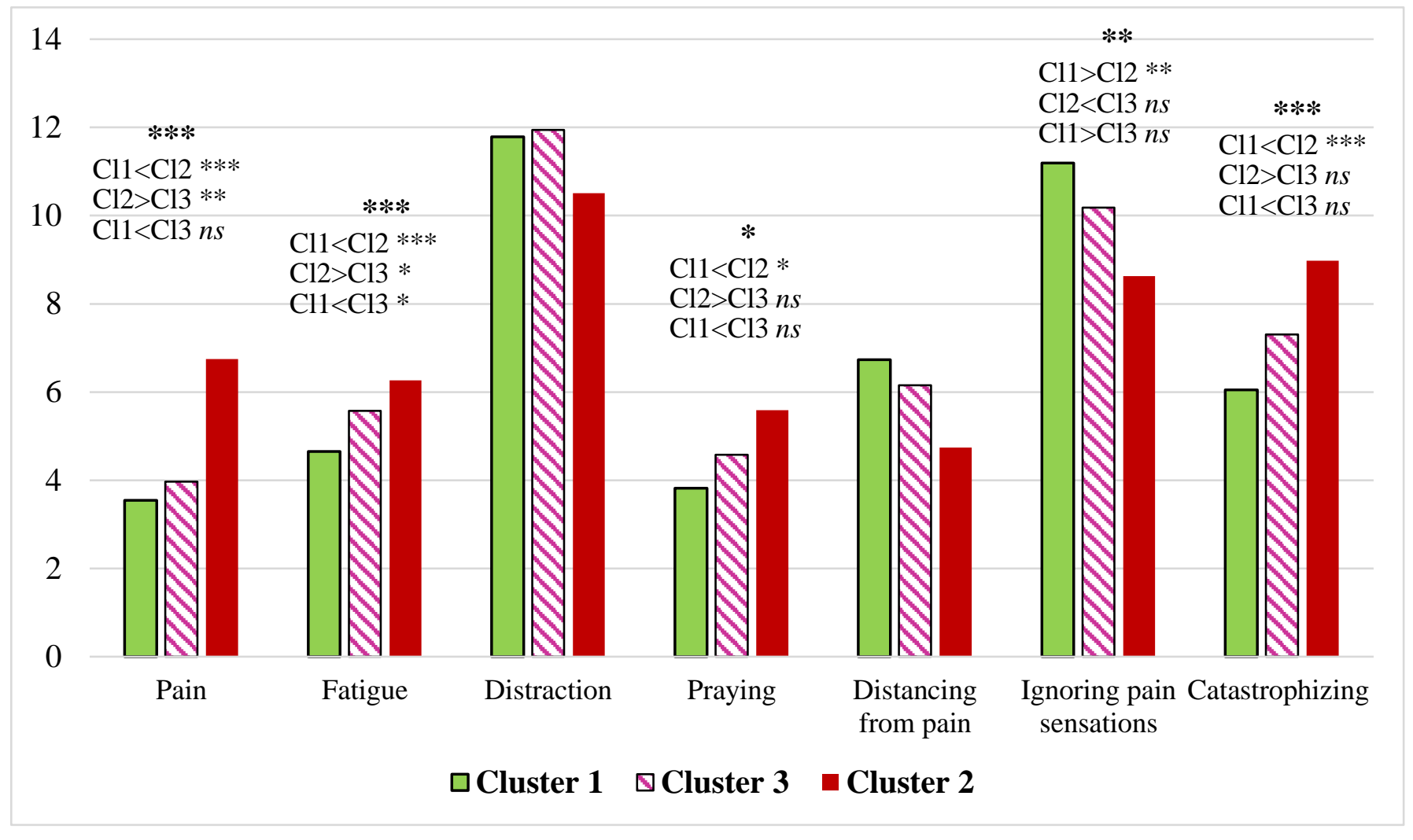

$n s$ : non-significant; $*: p<.05 ; * *: p<.01$ and $* * *: p<.001$

Cl1: cluster 1, $\mathrm{Cl} 2$ : cluster 2, and $\mathrm{Cl} 3$ : cluster 3 .

Figure 2: Pain, Fatigue, and Coping strategies of patients in the three clusters 